\title{
Plasma Coagulation Tests for Detection of Antiphospholipid Antibodies: What's Good, and What Might Be Improved?
}

\author{
Sukesh Chandran Nair ${ }^{1}$ (D) Tulasi Geevar $^{1} \cdot$ Rutvi Gautam Dave $^{1}$
}

Received: 11 June 2019/Accepted: 14 June 2019/Published online: 10 July 2019

(C) Indian Society of Hematology and Blood Transfusion 2019

DRVVT is a test to detect Lupus anticoagulant (LA) as part for investigation for Antiphospholipid syndrome (APS) along with Anticardiolipin (aCL) and Anti- $\beta 2$-glycoprotein-I (aß2GPI) antibodies.

According to the revised classification criteria, APS is diagnosed only if one clinical and one laboratory criteria are satisfied [1]. The clinical criteria could be either one or more clinical episodes of arterial, venous, or small vessel thrombosis or pregnancy morbidity/fetal losses. Laboratory criteria require detection of Antiphospholipid Antibody (APA) when all or either LA, aCL antibody or a 32 GPI antibody is positive on two occasions at least 12 weeks apart. Diagnosis of APS should be avoided if less than 12 weeks or more than 5 years separate positive APA test and the clinical manifestation. This is especially true for a positive LA test, considering the variables that affect this test $[1,2]$.

No single test is sensitive for all LA. The recommendation is to perform two different tests that represent different assay principles. The dilute Russell viper venom time (DRVVT) is the most robust and specific test in detecting LA and should be the first test considered. The second test should be a sensitive activated partial thromboplastin time (APTT) using low phospholipids. LA should be considered as positive if one of the two tests gives a positive result [3].

In this edition of the journal, Ramaraj et al. [4] and Ahuja et al. [5] have also found that sensitivity of DRVVT

Sukesh Chandran Nair

scnair@cmcvellore.ac.in

1 Department of Transfusion Medicine and Immunohaematology, Christian Medical College, Vellore, Tamil Nadu, India is superior as compared to other tests for LA. Ahuja et al. evaluated the performance of four LAC tests (APTT-LA, kaolin clotting time - KCT, dilute prothrombin time-DPT and DRVVT). They found that the sensitivity increased to $100 \%$ if the number of assays was increased to three by incorporating APTT-LA, DRVVT and KCT. However, the ISTH recommends only two screening tests since the risk of false-positive results is increased to an unacceptable level if more than two screening tests are performed. This is more so since the KCT and DPT both lack standardisation.

LA testing by DRVVT becomes significant as it helps identify triple positivity (positive LA, aCL and a $32 \mathrm{GPI}$ antibodies) which carries a much higher risk of thrombosis and pregnancy loss than patients with double or single positivity. Only some aß2GPI antibodies are pathogenic, namely those directed against Domain I of the $\beta 2 \mathrm{GPI}$ molecule [6]. Triple positivity identifies the pathogenic autoantibody (anti-Domain I of $\beta 2 \mathrm{GPI}$ ) present in patients with definite APS. Studies have shown that sole positivity of LA with negative aCL and aß2GPI antibodies is not associated with thromboembolic events [7].

A positive LA test can be caused by the presence of aß2GPI antibodies, antiprothrombin antibodies or antibodies to other cofactors. $\beta_{2}$ GPI-dependent LA highly correlates with thrombosis in APS [8]. A reduction in final calcium concentration, from 10 to $5 \mathrm{mM}$ increases coagulation times of dRVVT in plasmas of patients with a 32 GPI antibodies, while it shortens coagulation times in patients with aß2GPI-negative LA. This simple modification can thus be used to identify $\beta_{2}$ GPI-dependent LA [9].

DRVVT is important for the diagnosis of APS to detect triple positivity, but its variables demand proper standardization. Easiest thing is to report LA with a 32 GPI. If there is discrepancy between both, repeat DRVVT with 
lower concentration of calcium to potentially bring agreement between LA and aß2GPI. Though most of the DRVVT reagents contain Heparin Neutralisation reagent, it is recommended to do thrombin time on the samples before DRVVT testing to rule out presence and also gauge the amount of heparin that could be present.

Testing for LA should be limited to patients who have a significant probability of having the APS. Generalized searches as a part of investigation of accidentally prolonged APTT on asymptomatic individuals are highly discouraged to avoid the risk of obtaining false-positive results or detection of transient lupus. Transient Lupus can be present in inflammatory conditions like appendicitis, tonsillitis, adenoiditis, synovitis and usually disappears on repeat testing after 12 weeks [10].

Thus, tests for lupus should be performed only if there is at least one clinical criterion (history of thrombosis/recurrent pregnancy loss) for APS. The positive test should be repeated after at least 12 weeks to avoid transient lupus due to associated inflammation. This phenomenon can also be seen in patients with thrombosis, but 12 weeks later it will become clear if the cause for thrombosis was LA or other risk factor.

\section{References}

1. Miyakis S, Lockshin MD, Atsumi T, Branch DW, Brey RL, Cervera $R$ et al (2006) International consensus statement on an update of the classification criteria for definite antiphospholipid syndrome (APS). J Thromb Haemost 4(2):295-306
2. Tripodi A (2007) Laboratory testing for lupus anticoagulants: a review of issues affecting results. Clin Chem 53(9):1629-1635

3. Pengo V, Tripodi A, Reber G, Rand JH, Ortel TL, Galli M et al (2009) Update of the guidelines for lupus anticoagulant detection. J Thromb Haemost 7(10):1737-1740

4. Ramaraj A, Negi VS, Kar R (2019) Assessment of normative range and deriving cut-off values for lupus anticoagulant testing: an experience from a tertiary care center in Southern India. Indian J Hematol Blood Transfus 25:1-4

5. Ahuja A, Tyagi S, Pati HP, Saxena R, Somasundaram V, Manivannan P et al (2019) Utility of lupus anticoagulant assays (APTT-LA, KCT, DPT and DRVVT) in detection of antiphospholipid syndrome (APS) in high risk pregnancy cases. Indian $\mathrm{J}$ Hematol Blood Transfus 23:1-7

6. de Laat B, Pengo V, Pabinger I, Musial J, Voskuyl AE, Bultink IEM et al (2009) The association between circulating antibodies against domain I of beta2-glycoprotein I and thrombosis: an international multicenter study. $\mathbf{J}$ Thromb Haemost 7(11):1767-1773

7. Pengo V, Biasiolo A, Gresele P, Marongiu F, Erba N, Veschi F et al (2007) A comparison of lupus anticoagulant-positive patients with clinical picture of antiphospholipid syndrome and those without. Arterioscler Thromb Vasc Biol 27(12):e309-e310

8. de Laat HB, Derksen RHWM, Urbanus RT, Roest M, de Groot PG (2004) beta2-glycoprotein I-dependent lupus anticoagulant highly correlates with thrombosis in the antiphospholipid syndrome. Blood 104(12):3598-3602

9. Pengo V, Biasiolo A, Pegoraro C, Iliceto S (2004) A two-step coagulation test to identify antiß2-glycoprotein I lupus anticoagulants. J Thromb Haemost 2(5):702-707

10. Male C, Lechner K, Speiser W, Pabinger I (2000) Transient lupus anticoagulants in children: stepwise disappearance of diagnostic features. Thromb Haemost 83(1):174-175

Publisher's Note Springer Nature remains neutral with regard to jurisdictional claims in published maps and institutional affiliations. 